patient would benefit from other parts of the rehabilitation and wellbeing service.

Results We are currently in the process of collating the results of the first six months pilot in conjunction with our audit team. Provisional results appear to show that whilst patients may not show improvement physically, there is a demonstrable improvement in their mental health.

Conclusions The service delivery and outcome measures will be reviewed in accordance with the provisional findings of the pilot project.

\section{P-161 INPATIENT SUPPORTIVE SELF-MANAGEMENT INNOVATION - WELLBEING CAFÉ PILOT}

Margretta Davies, Vicky Gibson. Sue Ryder Hospice, Thorpe Hall, Peterborough, UK

10.1136/bmjspcare-2019-HUKNC.183

Background Rehabilitative palliative care can positively promote overall wellbeing and best practice highlights facilitating supportive self-management groups (SSMGs) (Hospice UK, 2015). The need for SSMGs was identified in our inpatient unit (IPU) patient, carer and staff feedback. The wellbeing café emerged as the most promising option. This enables isolated patients and carers opportunity to socialise and optimise their functional potential through tailored educational talks and activities.

Aims

- Promote wellbeing;

- Reduce social isolation;

- Offer SSMGs that are flexible and can be tailored to meet needs in the group;

- Teach symptom self-management strategies, enable sharing of peer support and tips;

- Task practice activity e.g. making own cup of tea in preparation for discharge.

Evaluation at 12 weeks will focus on pre- and post- sessions wellbeing scores, satisfaction and feedback comments.

Method October 2018 - February 2019: service evaluation, feedback, development of pilot.

March 2019 - May 2019: engagement with senior management and all hospice teams. Development of promotional material.

May 2019 - ongoing: Wellbeing café pilot commenced and is facilitated by staff and a volunteer. Services users are informed about the Wellbeing Café whilst on IPU and provided with a leaflet.

June 2019: Interim six -week evaluation, feedback to quality improvement group, meeting with marketing manager.

Results Anticipated results for the 12-week pilot is that wellbeing scores would be maintained or improved. Interim results at six weeks include:

- Attendance, 21;

- Feedback comments are extremely positive;

- $100 \%$ report that they have found the sessions helpful;

- $100 \%$ report that they would attend again.

Conclusion The Wellbeing Café has proved beneficial during this initial 6-week period. Evaluation comments are extremely positive in relation to subjective wellbeing. Streamlining the referral process, reviewing practicalities and time commitment involved in assisting service users to the café is required. The
Wellbeing Café's success and sustainability will be strengthened by nominating champions and continued hospice team engagement.

\section{P-162 SUPPORTED SELF-MANAGEMENT IN YOUNG ADULTS WITH PALLIATIVE CARE NEEDS}

Ros Cook, Philippa Sellar. St Christopher's Hospice, London, UK

\subsection{6/bmjspcare-2019-HUKNC.184}

Background Transition is defined as a purposeful and planned process of supporting young people to move from children's to adults' services (Together for Short Lives, 2012). The preparation and planning around moving on into adult services can be an uncertain time for young people with health needs. There is evidence of service gaps and young people may fail to engage with services without proper support (NICE, 2016). This leads to greater levels of dependence and isolation, with little opportunity for social situations. Personal autonomy and independence are frustrated.

Aims Supported self-management aims to potentiate a shift towards self-care and personalised care (NHS Long Term Plan, 2019). Evidence suggests that measuring individuals' activation; their level of knowledge, skills and confidence and then tailoring support through interventions that improve their activation, helps to empower and enables them to be in control of their own health and care (Hibbard \& Gilburt, 2014).

Supported Self-Management Programme consists of:

- Patient Activation Measure (PAM) to assess likelihood of being able to self-manage;

- Supportive resources to increase skills, knowledge and confidence;

- My Healthcare Journal.

Methods Following assessment of activation using the PAM, the young adults identify their goals and priorities and a personalised care plan is documented in 'My Healthcare Journal'; an intervention to support self-management. Other interventions the young adults are introduced to include self-management education, health coaching and access to community resources such as peer support and group based activities. Activation is re-measured together with assessment of satisfaction and achievement of personal goals and autonomy.

Results Increased personal autonomy and improved health outcomes are anticipated, together with greater effectiveness around resource allocation.

Conclusion Supported self-management provides a means of empowering young adults, enabling them to address goals and priorities. Resources are tailored to individual needs.

\section{P-163 RECOGNISING SPIRITUALITY: THE IMPACT OF TRAINING ON HEALTHCARE PROFESSIONALS SUPPORTING PATIENTS' SPIRITUAL NEEDS}

\footnotetext{
${ }^{1,2}$ Karen Groves, ${ }^{2}$ Barbara Jack, ${ }^{2}$ Mary O'Brien. 'Queenscourt Hospice, Southport, UK; ${ }^{2}$ Edge Hill University, Ormskirk, UK
}

\subsection{6/bmjspcare-2019-HUKNC.185}

Background Supporting patients spiritually as they approach the end-of-life is vital. If spiritual needs are unmet, patients are at increased risk of poorer psychological outcomes, quality 